\title{
Parental Influence, Gender Socialization and Career Aspirations of Girl Students: A Study in the Girls' Colleges of Upper Assam
}

\author{
Devika Phukan', Dr. Jyotiprasad Saikia² \\ ${ }^{1}$ Research Scholar, Dibrugarh University \\ ${ }^{2}$ Associate Professor, Department of Sociology, Dibrugarh University
}

\begin{abstract}
This study focuses on parental influence on gender socialization of girl students and its effects on their career aspirations in the girls' colleges of Upper Assam. The required data for the study have been collected from the higher secondary first year students of the girls' colleges of Upper Assam. These data were collected with the help of interview schedule. This study reveals that girls are mainly socialized according to their gender through the various activities and teachings of their parents. Moreover, various restrictions have been imposed on them after they attain puberty. All these have great effects on their personality as well as on their career aspirations.
\end{abstract}

Keywords: Girls, Gender Socialization, Career Aspiration, Gender Identity, etc.

\section{INTRODUCTION}

Career is considered as those actions taken by an individual in his or her lifetime in the path of his or her occupation. It can be defined as an individual's general course of actions through a phase of life, as in some profession (Dictionary.com). Barley (1989) defined career as a structural property of an occupation which could be identified as a sequence of positions held by an ideal practitioner. Career also refers to the pattern of work related experiences in the course of an individual's life (Greenhaus, 2000). Choosing a career is considered as a significant decision that influenced the entire future of an individual. Every individual carries the unique environment, personality and opportunity through the realization of which they make career choices. A person's career aspiration represents his or her orientation towards a particular occupation. There can be several factors affecting the career aspirations of an individual. It can be influenced by gender, socio-economic status and family support (Domenico and Jones, 2007). In addition to this factors passion, salary etc. also influence in the career choice of an individual. It has been found that family plays the most critical role in the career choice of individuals (Guerra and Brungart-Rieker, 1999; Lankard 1996; Mickelson and Valusco 1998). Various Career choice theories also indicate the role of family in the career choice of individuals. The Social Learning Theory indicates the possible influences the family has on career development of individual. In the family, it is the parents who play the important role in influencing upon the career choice of individuals. The parents can be considered as 'value socializers' in shaping their children's perceptions on occupation or career related decisions (Astin, 1984). Gender is considered to be a significant factor in the career choice of individual. The society sets different roles for both genders. The concept of gender is considered as a set of social practices which influenced the life of both male and female in the society. With the growth of the age, children develop a sense about themselves and their expected roles in the society through the process of socialization. Children learn to associate themselves with their gender roles through this process of socialization. This process of socialization is known as gender socialization. Because of this gender socialization process, girls use to perform such activities which reflect the social sex-role expectations (Looft, 1971b). During the process of their development from childhood to adolescence, individuals are exposed to various types of sexdifferentiated activities through which they learn gender socialization. It is the family, which plays the most significant role in gender socialization of children. And, in the family, it is the parents from whom the child first learns the meaning of being a male or female (Thorne, 1993). This gender socialization, at the very early stage of the girls' lives, has compelled them to prefer those careers that conform to the cultural stereotypes of female occupations. According to Adya and Kaiser (2005), parents play the influential role in career choice of children. Berk and Witt have mentioned that children of non-stereotypical parents have higher self-esteem, higher levels of identity achievement. 
Devika Phukan \&Dr. Jyotiprasad Saikia "Parental Influence, Gender Socialization and Career Aspirations of Girl Students: A Study in the Girls' Colleges of Upper Assam"

They have also mentioned that, girls, whose mothers are career-oriented, have higher educational aspirations and hold non-traditional vocational goals. These girls are found to be more engaged in typically masculine activities.

\section{Conceptual Understanding of Gender Socialization, Career Aspiration and Girl Students}

The study requires the conceptual definitions of the following key terms:

i. Career Aspiration: - Career aspiration can be regarded as the main and indispensable objectives of one's life. It is defined as an individual's orientation towards a desired goal under ideal conditions. It provides information about and individual's interests and hopes. However, in this study, the term 'career aspiration' refers to the various occupations and courses of study that students aspire to choose in their future as their career.

ii. Gender Socialization: - In this study, the term gender socialization refers to the process through which a child, with the help of the parents, learns the gender norms of a particular society and develop gender identity. The strongest influence on gender socialization of children seems to occur within the family, with parents passing on, overtly and covertly, their own beliefs about gender (Witt, 1997).

iii. Girls students:- Here, girls students refer to those students who are studying in Higher secondary classes (Arts and Science streams) in the girls' colleges of upper Assam.

\section{Significance and Limitations of the Study}

Girl students studying in the girls' colleges of upper Assam are exposed to variety of aspects included in the field of career choices. This study will help determine the factors and current process of career aspirations of girl students studying in the higher secondary classes. Moreover, since there is a lack of information available to girl students and educational institutions and other stakeholders concerning career opportunities, this study will provide information which can be used in promoting involvement of girls in different careers. Moreover, the educational institutions and other related organizations can also utilize that information for developing various career choices to girl students. Career Counselors can use the information from this study when counseling students in making career choices. But there are certain limitations of the study which can be mentioned below:

i. The present study is confined to the girl students studying in the girls' colleges of Upper Assam. Moreover, the respondents are from only Arts and Science stream. There is scope for further studies including the commerce stream also.

ii. The study is confined to some particular career options only. There is scope for study including certain other career options also.

iii. The study is confined with only the girl students as sample. A comparative study is highly required to understand the influence of gender socialization on career aspirations of girls. Therefore, in this study, both male and female students should have been considered as sample.

\section{OBJECTIVES OF THE STUDY}

The broad objectives of the study are to explore the influence of parents on gender socialization and its impact on the career aspiration of girl students studying in the girls' colleges of Upper Assam. However, the study includes the following specific objectives:

i. To find out the parental influence on gender socialization of the respondents.

ii. To find out the role of parents and gender socialization in the career aspirations of the respondents.

\section{Theoretical Perspective}

The present study has applied the theoretical perspectives of gender socialization in order to explore the career aspirations of girl students. Gender is a socially constructed term. It refers to the socially constructed distinction between male and female. ${ }^{1}$ It is a bundle of social practices which have significant influence upon the lives of both male and female members of our society. ${ }^{2}$ And, gender

\footnotetext{
${ }^{1}$ Nicholson, L. (1995). Interpreting Gender, Chicago University Press, Chicago.

${ }^{2}$ Saikia, J.P. (2010). Gender: Themes and Issues, Ajanta Prakashan, New Delhi.
} 
Devika Phukan \&Dr. Jyotiprasad Saikia "Parental Influence, Gender Socialization and Career Aspirations of Girl Students: A Study in the Girls' Colleges of Upper Assam"

socialization is the process through which an individual learns the social expectations and attitudes associated with his or her sex. There are several theories that explain the process of gender socialization. These are mainly Social learning theory, Cognitive approach and Psychoanalytical perspectives. According to social learning approach children learn gender appropriate and inappropriate roles through positive and negative reinforcement (Burn, 1996; Wharton, 2005). A girl playing with 'car' can be considered as inappropriate in our society. It also states that young girl learns what it means to be female by observing the behaviour, activities and roles of her mother (Kretchmar, 2009). In this study, respondents are asked questions regarding the gender socialization. It was also tried to find out whether girl respondents were forced to choose career on the basis of their gender identity. The cognitive approach of gender socialization states that individuals internalize gender meanings from the outside world and then with the help of those meaning they construct an identity for them. In this study specific attempts have been made by asking question like "do you feel shy to interact with male members of the society" etc. to the respondents. The third approach, psychoanalytical approach is different from both social learning and cognitive development theories. Wharton (2005), states that some aspects of gender identity are results of unconscious psychological processes. In this study, from the point of view of psychoanalytical approach, respondents were asked questions whether they are happy or not to identify themselves as a girl at the time of early childhood stage. Moreover, in the words of Chorodow, the key factor in the development of gender identity in people is their mother as children spend more time with mothers than fathers. Thus, girls by identifying themselves with their mothers easily learn how to be female (Stockard, 1999). Regarding this, the respondents were asked questions like "Do you want to be like your mother." With these perspectives of gender socialization, it has been tried to find out the influence of gender socialization on the career aspirations of girl students.

\section{Field and Methodology of the Study}

The population of the study includes all the girl students studying in the provincialised girls' colleges of Upper Assam. ${ }^{3}$ There are about 1000 girl students enrolled in higher secondary first year classes of the particularly selected colleges for the study. Girl students from each college were selected as sample for the study by using purposive sampling technique. The students were selected from the available students in the classroom during the field study. In this study, it has been considered that $40 \%$ sample would be representative and significant for drawing out the conclusion for the study. Thus, total 400 girl students studying in higher secondary first year classes in the selected girls' colleges have been selected as sample for this study. Keeping in view the main objectives of the study, only the girl students studying in higher secondary first year have been selected as respondents for the study. Descriptive survey method has been applied for the present study. Data required for the study have been collected both from primary and secondary sources. The primary data have been collected with the help of interview schedule. And, the secondary sources of data have been collected with the help of books, journals, theses, official records, websites, etc.

\section{Findings of the Study}

From the moment of birth, children may experience gender influences. In the process of their development they learn the concepts of gender self-concepts, gender beliefs, motives, etc. and thus involve themselves in gender specific activities. This process of gender socialization is transformed to them through their families, peers, media, schools, etc. (Wood \& Eagly, 2002). In this particular study emphasis is laid on the role of the parents in this regard.

\section{Teachings of Gender Identity by the Parents and Career Aspirations of the Respondents}

In this study, it has been asked to the respondents if they are taught gender identity teachings by their parents or not. 197 respondents out of 400 respondents; i.e. $49.25 \%$ are found to be taught different identity as girl at home by their parents. On the other hand, the rest of 203 , i.e. $50.75 \%$ of the respondents are not taught gender identity by their parents at home. out of those 197 respondents who are taught by their parents gender identities at home, $20(10.15 \%)$ of them are taught to wear different clothes specific to girls, $52(26.4 \%)$ respondents are taught to develop patience, $97(49.24 \%)$ respondents are taught to obey rules \& regulation of parents and $28(14.21 \%)$ are taught to stay calm

\footnotetext{
${ }^{3}$ Upper Assam is an administrative division of Assam. It is comprised of Dhemaji, Dibrugarh, Lakhimpur, Golaghat, Jorhat, Sibsagar and Tinsukia districts. (https://en.wikipedia.org/wiki/Upper_Assam_Division)
} 
Devika Phukan \&Dr. Jyotiprasad Saikia "Parental Influence, Gender Socialization and Career Aspirations of Girl Students: A Study in the Girls' Colleges of Upper Assam"

as girl. Here, the 197 respondents who are taught gender identity at home by the parents are found to be aspiring for the following careers: $85(43.14 \%)$ respondents prefer teaching career, $22(11.2 \%)$ of them prefer administrative careers, $27(13.7 \%)$ respondents prefer legal practice as a career, $16(8.1 \%)$ respondents prefer social service and $25(12.7 \%)$ respondents prefer self-employment. On the other hand, only $4(2.03 \%)$ respondents prefer medical as career, $1(0.5 \%)$ respondent prefers engineering as career, $7(3.5 \%)$ respondents prefer business as career, $3(1.5 \%)$ respondents prefer writing as a career and $7(3.5 \%)$ respondents prefer choreography as a career.

\section{Training of Household Activities to the Respondents by the Parents and their Career Aspirations}

Geisler (2009) has stated in his study that household activities are heavily gendered in home. Here, the larger responsibilities have been vested specially on girls. Indian girls are expected by their parents to do all kinds of domestic work (Parthasarthy, 1988). In this study, respondents are asked that whether they are trained by their parents to do household activities from childhood or not. It has been noticed that majority of the respondents, i.e. $285(71.25 \%)$ are trained by their parents to do household activities from childhood and only $115(28.75 \%)$ are not taught to do such activities by their parents. Out of 285 respondents, majority of the respondents, i.e. 207 (72.63\%) are trained by mother to do household activities. After that $44(15.44 \%)$ respondents are trained by father, $8(2.81 \%)$ are trained by brother and $14(4.91 \%)$ are trained by sister. Only $12(4.21 \%)$ of the respondents are trained by other family members to do household activities. It has been noticed that mothers play the significant role in training their daughters to do household activities. These household activities include cleaning the house, washing clothes, cooking food, helping mother in the kitchen, etc. These 285 respondents are generally aspiring for the following careers: $115(40.3 \%)$ respondents aspire for teaching as career, after that $37(13 \%)$ respondents aspire for legal practice, $36(12.6 \%)$ respondents for self-employment, $31(10.8 \%)$ respondents aspire for administrative career, $25(8.7 \%)$ respondents for social service, 14 (4.9\%) for medical career, $11(3.8 \%)$ respondents for engineering, 7 (2.4\%) respondents aspire for business as career, $5(1.7 \%)$ respondents for choreography, $3(1.05 \%)$ respondents for writing as career and only $1(0.35 \%)$ respondents aspires for politics as a career.

It has also been noticed that whether trained by the parents to do household activities or not, 318 (79.5\%) respondents perform household activities regularly by the respondents. The rest of the respondents, i.e. $82(20.5 \%)$ of them state that they do not perform household activities regularly at home. And here, out of those 318 respondents, 109 (34.3\%) respondents are compelled to do household activities by their mothers, after those 92 (29\%) respondents do the activities by their own self, and 59(18.5\%) respondents are compelled by their sisters. It has been further noticed that only 18 (5.6\%) respondents are compelled to do so by their fathers, 24 (7.5\%) respondents are compelled by their brothers and $16(5 \%)$ respondents are compelled by other family members like grandparents, uncle, aunt, etc.

In this study, the respondents are asked if their brothers help their mothers in household activities. In response to this question it has been found that 153 , i.e. $38.25 \%$ of the respondents mentioned that their brothers help their mothers in household activities. On the other hand, 247, i.e. $61.75 \%$ of the respondents' brothers do not help their mothers in doing household activities. Out of these 247 respondents, $127(51.4 \%)$ respondents mention that their brothers themselves do not want to work, 65 , i.e. $26.3 \%$ of the respondents mention that boys do not work, 33 , i.e. $13.3 \%$ of the respondents are of the view that their parents do not allow their brothers to work and the rest of the respondents, i.e. 22 (9\%) respondents mention that their brothers do not help their mothers in household activities because of other reasons like they believe that it will lower their position in the family, they find it uninteresting as well as unimportant, etc. It has been stated by Parthasarthy (1988) that all kinds of domestic works are expected to be done by the girls and on its contrary, boys are expected to do masculine works and tasks outside home.

Parents' Suggestions Regarding the Dress Code of the Respondents and Career Aspirations of the Respondents

In this study the respondents are asked whether they are suggested by their parents to dress differently or not. It has been found that $228(57 \%)$ of the respondents are suggested by their parents to dress 
Devika Phukan \&Dr. Jyotiprasad Saikia "Parental Influence, Gender Socialization and Career Aspirations of Girl Students: A Study in the Girls' Colleges of Upper Assam"

differently and the rest $172(43 \%)$ are not suggested to do so. Regarding the dresses of the respondents, it has been found that the parents want to consider the followings:

They want their girls to cover their whole body while dressing (23.25\%), to dress according to the norms of the society $(29.75 \%)$, to dress according to new trend $(20.25 \%)$ and to dress according to their comfort (26.5\%).

Further in this study, all the 400 respondents are asked whether their dress code ${ }^{4}$ have effects in their career development or not. It has been found that $125(31.25 \%)$ respondents have said that the way they dress can have effect on their career development, whereas, $275(68.75 \%)$ of them are of the view that their dressings don't have any effect on their career development. Out of those 125 respondents who believe that their particular dress code as girl have effects up on their career development $31(24.8 \%)$ respondents are of the view that comfortable dressings style can help them in moving freely and thus help in their career development. $10(8 \%)$ of the respondents are of the view that decent dress can avoid unnecessary complexities in work place, $20(16 \%)$ respondents are of the view that appropriate dress can make them look smarter in workplace and $26(20.8 \%)$ are of the view that proper dressing reflects individual's personality. Majority of the respondents i.e. .38 (30.4\%) are of the view that comfortable and smart dresses give them self-confidence and thus help them in their career development.

\section{Expectations of the Society Regarding their Behavior after Attaining Puberty}

Majority of the respondents, i.e. $252(63 \%)$ are of the view that they are compelled to behave in different ways as per expectation of the society. On the other hand, the rest of the respondents, i.e. 148 (37\%) have said that they are not compelled to behave differently after attaining puberty. Those 252 respondents are also asked to state to expected behaviours from them after attaining puberty. It has been found that majority of the respondents, i.e. 56 (22.2\%) are asked not to do some activities which are labeled as male centric activities. After that, 52, i.e. $20.6 \%$ are asked to observe proper rituals, 41 , i.e. $16.3 \%$ are asked to maintain proper dress code, 20 , i.e. $7.9 \%$ are asked not to discuss sexual activities openly and 15, i.e. $5.9 \%$ are asked to behave in other different ways. Equal number of respondents, i.e. 34 (13.5\%) are asked not to mix up with male members and to stay inside the house mostly. Out of those 252 respondents, $198(78.6 \%)$ are compelled to behave differently by their mothers after attaining puberty. After that $36(14.3 \%)$ of the respondents are compelled by their relatives, $10(4 \%)$ are by their fathers and only $8(3.1 \%)$ of the respondents are compelled by their neighbors to behave differently after attaining puberty. Thus, mothers play a significant role in gender socialization of girl students.

Out of the total 400 respondents it has been found that, 289, i.e. $72.25 \%$ of the respondents attend college during menstruation. On the other hand, the rest 111, i.e. $27.75 \%$ of the respondents do not attend college during menstruation. Among these 111 respondents who do not attend college during menstruation, 39 , i.e. $35.1 \%$ of the respondents feel hesitation to mix up with others in college. After that, 33 , i.e. $29.7 \%$ of the respondents' parents do not allow going to school during menstruation and 26 , i.e. $23.4 \%$ of the respondents have mentioned that they did not attend college during menstruation because it is considered as a rule made by the society to avoid activities outside home during menstruation. The rest of 13, i.e. $11.7 \%$ of the respondents did not attend college during menstruation because of other reasons like physical weakness, uneasiness etc.

\section{Development of Personality Traits by Gender Socialization and Career Aspirations of the Respondents}

In this study, it has been asked to those 279 respondents, who have developed personality traits ${ }^{5}$ due to gender socialization, to mention the types of the particular traits they have develop. It has been noticed that $59(21.1 \%)$ respondents develop anxiety, $56(20.1 \%)$ respondents develop shyness, 38 (13.6\%) developed stress, 31 (11.1\%) develop boredom and $28(10 \%)$ respondents develop any other personality traits due to gender socialization. On the other hand, majority of the respondents, i.e. 67 (24\%) respondents develop inferiority complex due to gender socialization. It has been found that 159 $(39.75 \%)$ of the respondents have got problem from their personal traits to involve in a career. 46

\footnotetext{
${ }^{4}$ Dress code: The general style of what one wears.

${ }^{5}$ Personality Traits: It is the characteristics of an individual which is specific to a particular individual and which reflects the feelings, thoughts and behaviours of an individual.(Diener and Lucas), http://nobaproject.com /modules/personality-traits
} 
Devika Phukan \&Dr. Jyotiprasad Saikia "Parental Influence, Gender Socialization and Career Aspirations of Girl Students: A Study in the Girls' Colleges of Upper Assam"

(29\%) of them have problem to talk to new people due to their personal traits. After that 39 (24.5\%) of the respondents have problem to adjust with new people, $24(15.1 \%)$ of the respondents have problem to open up freely in front of others and $14(8.8 \%)$ of the respondents have any other problem to involve in a career due to their personal traits. On the other hand equal number of respondents, i.e. $18(11.3 \%)$ have problem to initiate new work and plan new programs due to their personal traits.

Mojgan and others (2011) have claimed that trait like anxiety is closely associated with career indecision of an individual.

\section{CONCLUSION}

Parents play a significant role in the gender socialization of the respondents. Most of the respondents are taught gender identity by the teachings of their parents. These gender teachings have developed certain traits like shyness, anxiety, low self-esteem, boredom, etc. in the respondents. It has been noticed that these traits have affected in the career aspirations of the respondents. Moreover, some of the respondents are suggested by their parents regarding their dress style also. Starting of menstruation has also changed the expectations of the society towards the respondents. They are compelled to behave in certain ways because of which sometimes they are unable to attend the colleges. It has further been found that mothers have significant influence upon teachings them to behave in socially expectable ways during menstruation period. It has created certain problems like mixing up with other members, physical weakness, etc. It has been found that these suggestions also have effects upon the career aspirations of the respondents.

\section{REFERENCES}

[1] Adya, M \&Kaiser, K.M.(2005). Early determinants of women in IT workforce: A model of girl's career choice. Information Technology and People, Vol 18(3),pp.-230-259.

[2] Barley, S. (1989), "Careers, identities and institutions: the legacy of the Chicago School of Sociology", in M. Arthur, D. Hall, and B. S. Lawrence eds. Handbook of Career Theory, Cambridge, Cambridge University Press, pp. 41-65.

[3] Burn, S.M. (1996). The social psychology of gender, New York,: McGraw-Hill, Inc.

[4] Domenico, D. M. and Jones, K. H. (2007): Career Aspirations of pregnant and parenting adolescents, Journal of Family and Consumer Science Education, 25 (1), pp. 24-33.

[5] Geisler, G. \& Pardiwalla, M. (2009). Gender Socialization in the Home: Its impact on boys' achievement in primary and secondary schools. Human Development Department (OSHD), African Development Bank, 2009. Pp.16.

[6] Greenhaus, J. H. \& Callanan, G. A. (2006). Encyclopedia of Career Development. Sage Publications, p-325.

[7] Guerra AL and Braungart-Rieker JM (1999): Predicting career indecision in college students: The roles of identity formation and parental relationship factors. The Career Development Quarterly, (March), 47; pp. 12-18.

[8] Kretchmar, J. (2009). Gender Socialization. Research Starters, Academic Topic Review, EBSCO Publishing Inc.

[9] Lankard, B. A. (1996). Job training versus career development: What is voc ed's role? ERIC Clearinghouse on Adult, Career and Vocational Education (ED395217)

[10] Looft, W. R. (1971).: Sex differences in the expression of vocational aspirations by elementary school children, Developmental Psychology, 5, 366.

[11] Mickelson, R. and Velasco, A. (1998): Mothers and Daughters Go to Work: The Relationship of Mother's Occupations to Daughters' Career Aspirations. Paper presented at the Annual Meeting of the American Educational Research Association, pp. 13-17, San Diego, C.A.

[12] Mojgan, F.N., Kadir, R.A. \& Soheill, S. (2011). The relationship between state and trait anixiety with career indecision of undergraduate students. International Educational Studies, Vol. 4. (3), pp. 31-35. 
Devika Phukan \&Dr. Jyotiprasad Saikia "Parental Influence, Gender Socialization and Career Aspirations of Girl Students: A Study in the Girls' Colleges of Upper Assam"

[13] Parthasarthy, V. (1988). "Socialization, Women and Education: An Experiment." In: K. Charana (Ed.), Socialization, Education and Women (pp. 8-30) New Delhi: Nehru Memorial Museum and Library.

[14] Stockard, J. (1999). Gender Socialization. In J.S. Chaftez (Ed.). The Handbook of the sociology of gender (pp. 215-227). New York, NY: Plenum Publishers.

[15] Thorne, B. (1993). Gender Play: Girls and Boys in School, New Brunswick, NJ: Rutgers University Press.

[16] Wharton, A.S. (205). The Sociology of gender: An introduction to theory and research. Malden, MA: Blackwell Publishing.

[17] Wood, W. \& Eagly, A.H. (2002). Across-cultural analysis of the behaviour of women and men: Implications for the origins of sex-differences. Psychological Bulletin, 128, pp. 699-727.

\section{AUTHORS' BIOGRAPHY}

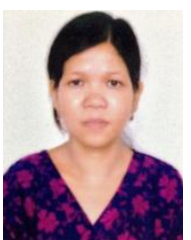

Devika Phukan, is a research scholar in Dibrugarh University. She has completed her Masters from Gauhati University and Bachelor degree from Cotton College. She has the experiences of teaching in higher secondary, degree level (regular) and master degree level under distance education course.

Dr. Jyotiprasad Saikia, is an Associate professor in the Department of Sociology in Dibrugarh University. He is the author of the book -Youth and career aspiration and many other textbooks in vernacular language for the students of Sociology. 